Japanese Journal of Physiology, 33, 309-322, 1983

\title{
Activities of Single Precentral Neurons of the Monkey during Different Tasks of Forelimb Movements
}

\author{
Ken'ichi Matsunami and Ikuma Hamada \\ Department of Neurophysiology, Primate Research Institute, \\ Kyoto University, Inuyama, Aichi, 484 Japan
}

\begin{abstract}
The neuronal activity in the motor cortex of the rhesus monkey was investigated in three different tasks performed with finger, wrist, and arm movements. A total of 125 neuronal activities were analysed. They were classified into five groups in terms of muscular contractions provoked by intracortical stimulation; neurons related to contractions of finger, wrist, elbow, shoulder, or trunk muscles. The neuronal activities in three tasks performed with finger, wrist, or arm movements were investigated for each group. Most of the neurons related to the contractions of elbow, shoulder, or trunk muscles were associated solely with arm movement. Smaller numbers of neuronal activities changed their firing frequencies in association with two or three tasks. Neurons related to the contractions of finger and wrist muscles showed various firing patterns in the three tasks; some responded to a single task with wrist or arm movement, while others changed their activities in association with more than one task. The presence of multi-task related neurons is discussed with respect to the multisegmental termination of corticospinal axons in the spinal cord.
\end{abstract}

Key Words: precentral neuron, multiple task, monkey.

Since the first application of recording unit activity from a chronic operantly conditioned monkey (EvARTs, 1965), various experiments have investigated neurons in the motor cortex. In most experiments, however, neuronal activities were studied with respect to a single motor paradigm of relatively simple movement; finger movement (SMITH et al., 1975), extension-flexion or rotatory movements at the elbow or wrist joint (CONRAD et al., 1975; EvarTs, 1966; Fromm and EvarTs, 1977; HAMAdA and Kubota, 1979; MurPhy et al., 1978, 1982; SCHMidt et al., 1975), pull or push-pull paradigm of a forelimb (EvarTs, 1973; EVARTS and TANJI, 1976; Lemon, $1981 \mathrm{a}, \mathrm{b}$; Lemon and Porter, $1976 \mathrm{a}, \mathrm{b}$; LeMON et al., 1980; Porter and LEWIS, 1975; PORTER et al., 1971), or correction movements to compensate for external disturbance(EVARTS, 1973; EVARTS and TANJI, 1976; TANJI and EVARTS, 1976).

Microstimulation or intra-axonal HRP injection conducted on a corticospinal

Received for publication July 8, 1982

松波謙一, 浜田生馬 
neuron demonstrated that its fiber gave off numerous collaterals into several spinal segments (Asanuma et al., 1979; HAYes and RUSitOni, 1981; Scheibel and Scheibel, 1966; Shinoda, 1978; Shinoda and Yamaguchi, 1978; Shinoda et al., 1976, 1979, 1981). The real functions of such a large divergence of a single corticospinal neuron are still unknown, but it may be suggested that a single corticospinal neuron controls not only the movement of a single muscle, but also movements of several muscles. Recently, LEMON reported that some cortical neurons in the motor cortex which discharged during a movement of the fingers, increased their firing only when the wrist was in one particular orientation position of the arm (1981b). However, he did not determine whether the cortical neurons related to fingers were related to the arm or shoulder muscles. It is desirable to determine whether motor cortical neurons associated with distal forelimb movements are also related to the proximal forelimb muscle or not.

Using a spike-triggered averaging technique, FETZ and his colleagues recently demonstrated that a corticospinal (corticomotoneuronal) cell innervated disynaptically several muscles (Fetz and Cheney, 1978, 1979; Fetz and FinocChio, 1971, 1975). They used a simple task to grip a handle in an isometric condition, and their analysis was restricted to a limited number of forearm muscles. In order to demonstrate simultaneous innervation of a neuron to distal and proximal forelimb muscles, it is necessary to study single neuronal activity in the motor cortex, in association with different motor tasks which involve different zones of forelimbs.

The present study was designed to ascertain the existence of multi-task related neurons in the motor cortex, to determine their links to muscles, and to reveal distribution of the multi-task related neurons in pyramidal and non-pyramidal tract neurons (PTNs and non-PTNs).

In principle, the results of the present study fit the concept of the somatotopic organization in the motor cortex (KWAN et al., 1978; Strick and Preston, $1982 \mathrm{a}, \mathrm{b}$; WoOLSEY, 1958). Most neurons related to proximal muscles were chiefly associated only with arm movement. Smaller numbers of neurons of this group changed in association with finger or wrist movements, in addition to arm movement. Neurons related to distal muscles, however, showed various types of responses to the three movements. Some neurons changed their activities in relation to only one of the three movements, while others were associated with two or three movements. The physiological significance of multi-task related neurons is considered in Discussion.

\section{METHODS}

The method of recording and analyzing unit activity used in previous reports (Matsunami and Hamada, 1978, 1981) was employed in this study. However, attention was focused on the relation of neuronal activity to three tasks (finger, wrist, and arm tasks) performed with the forelimb contralateral to the recording cortex. 
A brief description of method is given here. Consult previous papers for a more detailed description (MATSUnAmi and HAMADA, 1978, 1981).

Tasks. Two rhesus monkeys were used. Each monkey, sitting in a monkey chair, was trained to master three different tasks performed with finger, wrist or arm movements that required activity of the muscles around the respective joints ( $c f$. MATSunAmi and HAMAda, 1981). In the finger task, the monkey thrust its index finger into a small hole in a panel in front of the monkey, and depressed with finger flexion a small lever switch behind the hole. After nine sequential closings of the switch, the monkey was reinforced with a drop of juice (fixed ratio). In the wrist task, the monkey used its wrist to depress a stiffer lever switch protruding toward him from the panel, also at a fixed ratio at nine presses. In the arm task, the monkey gripped a handle and moved it in a horizontal arc alternatively between two target zones $60^{\circ}$ apart. The monkey had to hold the handle in the target positions for half a second. In this task, the two kinds of movements, outward and inward were treated differently in the histograms: in the outward movement, the monkey moved the handle from medial to lateral, while in the inward movement, the handle was moved in the opposite direction. The monkey was rewarded with the fixed ratio of nine.

When the monkey had learned the tasks, surgery was performed. The monkey was anesthetized with sodium pentobarbital $(40 \mathrm{mg} / \mathrm{kg}$ body weight). A hole was made in the skull over the hand-arm area of the motor cortex $(A=14$, $L=15)$. The dura was intact. A stainless steel cylinder (i.d. $=18 \mathrm{~mm}$ ) was fixed to the skull at the edge of the hole, and served as a mount for a hydraulic micromanipulator (OM-8; Narishige Kagaku Co.). At the same time, a bipolar stimulating electrode was chronically implanted in the bulber pyramid $(A=0)$ for identification of PTNs.

Recordings. Recordings of neuronal activities were made from the motor cortex with a Pt-Ir microelectrode coated with molten glass (1-3 M 2 ), while the monkey was performing the three tasks. After unit recording had been finished in a track, intracortical stimulation (ICS) was delivered through the recording electrode at the sites where units were recorded. The ICS provoked muscular contractions, which enabled functional correlation of neurons with muscles. Threshold current ranged from $7 \mu \mathrm{A}$ for a thumb flexion to over $700 \mu \mathrm{A}$ for deep truncal muscles, and was limited to less than $1 \mathrm{~mA}$. The reasons for a higher threshold for stimulation were given in detail in the previous report (MATSUNAMI and Hamada, 1981).

Data analysis. Recordings of neuronal activities and other signals were stored on a 4-channeled FM-magnetic tape for later use in an off-line analysis by a minicomputer (PDP-12). Peri-movement histograms of each unit were made for the three different tasks of finger, wrist, and arm movements. Bin width was $10 \mathrm{msec}$ for finger and wrist movements and $20 \mathrm{msec}$ for arm movement. Every 25 bins were alloted before and after the onset of movements. $F$-tests were performed on 
the histograms to determine if the units were related to the movements (MATSUNAMI and HAMADA, 1981). The significance level was set at $0.1 \%$ for all tasks. A stricter criterion than was used in the previous papers was adopted to collect units more related to prime movers or their dominant synergists. According to this criterion, 125 neurons were defined as related to at least one of the three tasks.

\section{RESULTS}

A total of 197 movement-related neuronal activities were recorded in the motor cortices of the two monkeys. Of these, 125 neurons were selected for analysis in this report ( $c f$. METHODs), because they were significantly associated with at least one of the three task performances ( $c f$. Methods). ICS was delivered at the recording sites in order to determine muscles connected with regions around the neurons. The 125 neurons were sorted into 5 groups according to movements elicited by ICS; finger- wrist-, elbow-, shoulder, or trunk-groups.

The firing pattern of neurons was investigated with respect to three tasks performed with finger, wrist or arm. The 125 neurons were classified into 7 groups according to their firing patterns in the three tasks. Three groups were related to only one of the three tasks, e.g., to finger, wrist, or arm movement. Another three groups were related to two tasks; to finger and wrist, finger and arm, or wrist and arm tasks. The remaining group was related to all three tasks. By combining these two methods of classification, a matrix with 35 elements $(5 \times 7)$ was constructed to categorize the 125 neurons (see Table 1).

\section{Examples of firing patterns during tasks}

Figures 1-3 show example responses of neurons of finger-, elbow-, and trunkgroups during three tasks. Neurons in the wrist- and shoulder-groups are not presented, because their discharge features were similar to one of these groups (cf. Table 1).

Figure 1 shows response patterns of three neurons of finger-group to three different tasks performed with the forelimb. The neuron in column A responded only to the wrist task, and did not discharge during either the finger or arm (OUT or IN) task. The neuron in column B responded to the arm task during outward (OUT) movement, but not to the other two tasks. Although, the activity was slightly modulated during both tasks ( $1 \%$ significance level), this neuron was considered to be related solely to arm movement ( $c f$. Methods). The neuron in column $\mathrm{C}$ changed its activity during all three tasks performed with finger, wrist, or arm. In the performance of the arm task, this neuron increased discharge rate prior to the movement in the outward direction (OUT), but did not change the activity in the inward direction (IN). We could not obtain finger-neurons which were only related to the finger task ( $c f$. Table 1). This point will be referred in Discussion. 

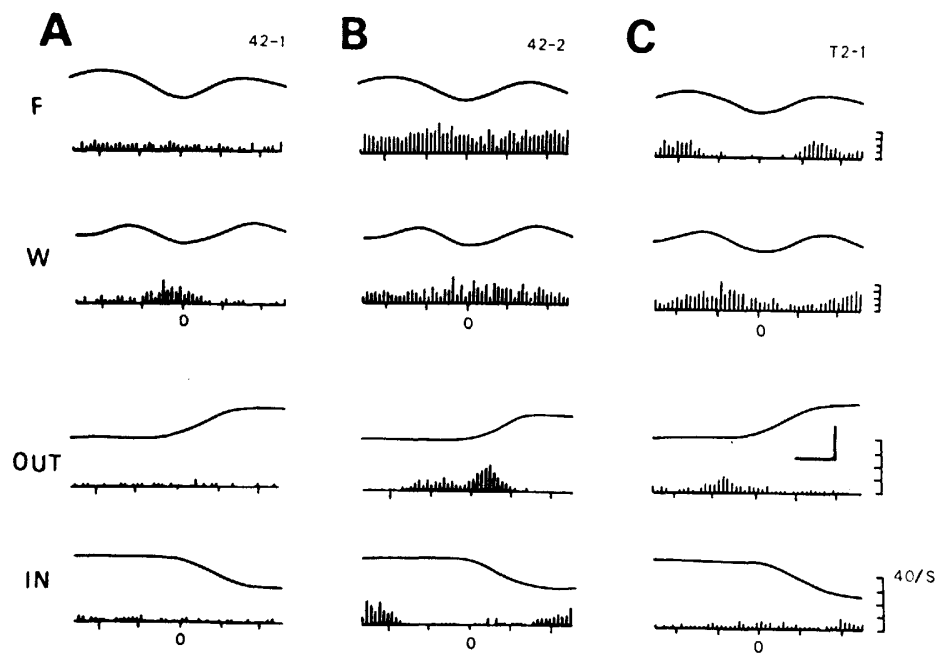

Fig. 1. Response patterns of cortical neurons in the finger-group to three tasks. A, B, and $\mathrm{C}$, different neurons; F, finger task; W, wrist task. OUT, arm task (outward movement); IN, arm task (inward movement). In each frame, the upper trace shows the trajectory of lever ( $\mathrm{F}$ and $\mathrm{W}$ : downward swing of the levers, were denoted as downward deflection), or handle movement, and the lower part is a perimovement histogram of neuronal activity. Horizontal bar, $50 \mathrm{msec}$ for finger (F) and wrist (W) tasks and 100 msec for arm task (IN and OUT). A vertical bar denotes $40^{\circ}$ for displacement of arm task. Zero denotes the onset of movement.

A similar analysis was conducted on neurons of the elbow-group as demonstrated in Fig. 2. The neuron in column A increased its discharge rate in the arm task during outward (OUT) movement, but not with finger, or wrist tasks. Meanwhile, the neuron in column B changed its activity in association with all three tasks.

Figure 3 demonstrates similar results for neurons in the trunk area. The neuron in column A fired only during the arm task, while the neuron in column B discharged in all three task performances. It was concluded from Figs. 1-3 that each group contained various types of neurons regarding the three tasks, even though ICS provoked contraction of distal, proximal forelimb, or trunk muscles in respective groups.

\section{Characteristics of cortical neuron activity in the three tasks}

Various kinds of neurons were found in each group in spite of the response characteristics to ICS, but it was expected that the majority of finger- or wristneurons would be associated more strongly with the finger and wrist than with arm tasks, while shoulder- and trunk-neurons are associated with arm tasks other than finger or wrist tasks. A quantitative analysis was conducted in these respective group. In each of the 5 groups classified under ICS muscular contractions, 

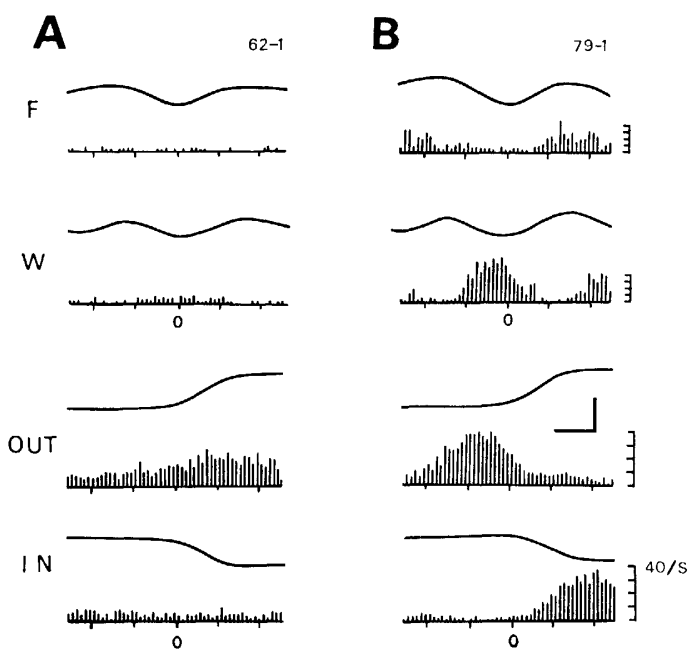

Fig. 2. Response patterns of cortical neurons in the elbow-group. In $\mathbf{A}$ and $\mathbf{B}$, different neurons are illustrated. F, finger task; W, wrist task; OUT, arm task (outward movement); IN, arm task (inward movement). In each frame, the upper trace shows the trajectory of a lever or handle movement and the lower part shows a perimovement histogram of neuronal activity. A horizontal bar denotes $50 \mathrm{msec}$ for finger (F) and wrist (W) tasks and is $100 \mathrm{msec}$ for arm (OUT and IN) movements. A vertical bar denotes $40^{\circ}$ for handle displacement in the arm task. Zero denotes the onset of movement.
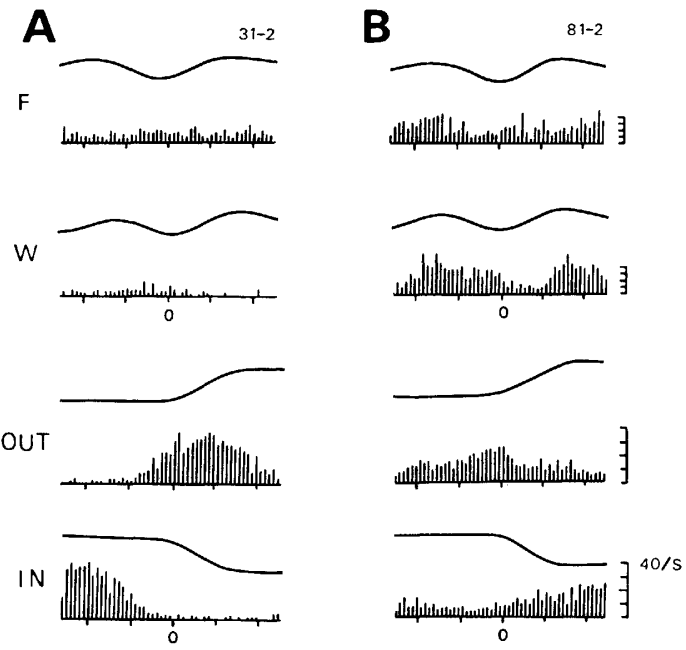

Fig. 3. Response patterns of cortical neurons in the trunk-group. A and B, different neurons; F, finger task; W, wrist task; OUT, arm task (outward movement); IN, arm task (inward movement). In each frame, the upper trace shows the trajectory of a lever or handle movement and the lower part shows a perimovement histogram of neuronal activity. A horizontal bar denotes $50 \mathrm{msec}$ for finger (F) and wrist (W) tasks and 100 msec for arm (OUT and IN) movement. A vertical bar denotes $40^{\circ}$ for handle displacement in the arm task. Zero denotes the onset of movement. 
Table 1. Relation of neuronal firing patterns and muscular contractions evoked by ICS.

\begin{tabular}{lcccccccc}
\hline \multirow{2}{*}{ ICS } & \multicolumn{7}{c}{ Task } \\
\cline { 2 - 9 } & F & W & A & F+W & F+A & W +A & F+W + A & $\begin{array}{c}\text { Total } \\
(\%)\end{array}$ \\
\hline Finger & 0 & 1 & 4 & 2 & 2 & 3 & 7 & 19 \\
Wrist & 0 & $(5.3)$ & $(21.1)$ & $(10.5)$ & $(10.5)$ & $(15.8)$ & $(36.8)$ & $(100)$ \\
& & $(7.4)$ & $(14.8)$ & $(7.4)$ & $(14.8)$ & $(37.0)$ & $(18.5)$ & $(100)$ \\
Elbow & 0 & 1 & 12 & 0 & 0 & 2 & 3 & 18 \\
& & $(5.5)$ & $(66.7)$ & & & $(11.1)$ & $(16.7)$ & $(100)$ \\
Shoulder & 1 & 2 & 25 & 0 & 4 & 6 & 7 & 45 \\
& $(2.2)$ & $(4.4)$ & $(55.6)$ & & $(8.9)$ & $(13.3)$ & $(15.6)$ & $(100)$ \\
Trunk & 0 & 1 & 8 & 0 & 1 & 3 & 3 & 16 \\
& & $(6.3)$ & $(50.0)$ & & $(6.3)$ & $(18.7)$ & $(18.7)$ & $(100)$ \\
Total & 1 & 7 & 53 & 4 & 11 & 24 & 25 & 125 \\
& $(0.8)$ & $(5.6)$ & $(42.4)$ & $(3.2)$ & $(8.8)$ & $(19.2)$ & $(20.0)$ & $(100)$ \\
\hline
\end{tabular}

F, finger task; W, wrist task; A, arm task. Finger, wrist, elbow, shoulder, and trunk at the far left column denote parts of the body where muscle contraction was observed by intracortical stimulation. Figures without parentheses are the numbers of neurons. Figures in parentheses are percentage values of each row.

neurons were further classified into 7 groups according to activities associated with three tasks (see Table 1).

In each row of Table 1, neurons with similar contractile properties by ICS were presented, and in each column, neurons with similar discharge patterns during the three tasks are given. The figures in parentheses are the percentage values of the group in each row.

Table 1 shows that 19 of 125 neurons $(19 / 125,15.2 \%)$ were related to contraction of finger muscles. Similarly, $27(21.6 \%)$ were wrist-group, $18(14.4 \%)$ were elbow-, $45(36.0 \%)$ were shoulder-, and $16(12.8 \%)$ were trunk-group. It can be concluded that each type of neuron was evenly distributed among the 5 groups, though the shoulder-group had a slightly larger percentage. Table 1 demonstrates that the neurons of elbow-, shoulder-, and trunk-groups were primarily related to the arm task. Very few neurons in these groups changed their activity only in finger or wrist tasks, or in combination of the three tasks. On the other hand, finger- and wrist-groups were composed of various types of neurons in response to the three tasks. Nearly half of the neurons in the finger-group changed their activities only during a single task. Another half responded either during two tasks, or during all three tasks. The most common type of the finger-group $(7 / 19,36.8 \%)$ was associated with all three tasks $(\mathrm{F}+\mathrm{W}+\mathrm{A})$. Among these seven neurons, two were of such a type as shown in Fig. 1C; with increase in activity during an arm movement in one direction and no change in another. Another two showed a reciprocal relationship of activity to movements; an increase in activity in one direction of movement and a decrease in another. The remaining three did not change 
activities in relation to movement, but increased discharge rate during holding of the handle in both start and target zones. Surprisingly, no neuron of the finger group was specifically activated during the finger task alone $(F)$. But two neurons $(10.5 \%)$ were associated with both finger and wrist tasks $(F+W)$. Another two, with finger and arm tasks $(\mathrm{F}+\mathrm{A})$, one showing a reciprocal change of activity with arm movements, and the other, increasing activity in one direction, but with no change in the opposite direction.

Neurons of the wrist-group showed a similar pattern of activities to the three tasks. But the most common type was associated with wrist and arm tasks $(\mathrm{W}+\mathrm{A})$ $(10 / 27,37 \%)$. Eight of them changed their activities during arm movements: increases in activities in one direction but decreases or no changes in the opposite direction. Two others changed activities during holding of the handle. The next common type were those associated with all three tasks $(5 / 27,18.5 \%)$. These five showed a reciprocal change of activity in relation to direction of movements. Only two wrist-neurons $(2 / 27,7.4 \%$ ) were specifically associated with the wrist task (W) alone.

While Table 1 contains detailed numerical information about the relationship of neurons to the three tasks, Fig. 4 is provided for better intuitive understanding of the results. Figure 4 clearly demonstrates that most of the elbow-, shoulder-, and trunk-neurons were involved solely in the arm movement, and smaller numbers responded to two or three tasks. On the other hand, neurons of finger- and wristgroup showed various types of responses to the three tasks. But the majority were related to more than two tasks. The most common of the finger-group were those related to all three tasks $(7 / 19,36.8 \%)$, and of the wrist group were those related to wrist and arm tasks $(10 / 27,37.0 \%)$.

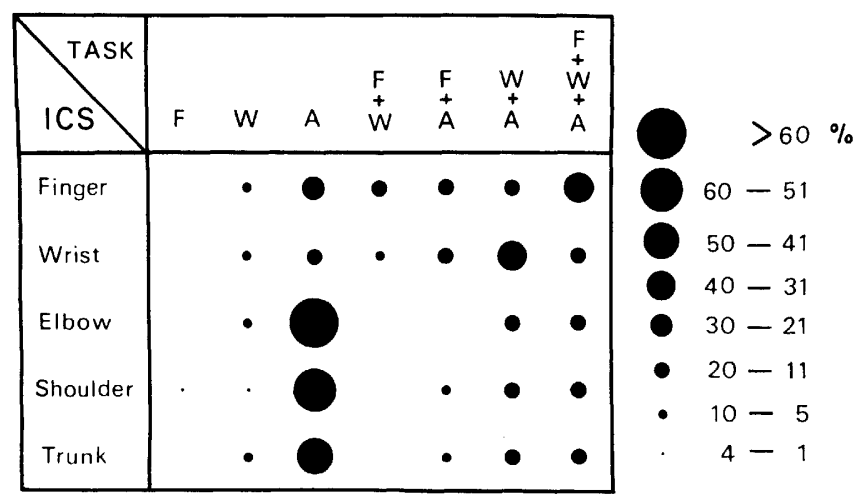

Fig. 4. Graphic illustration of populations of multi-task related neurons in respect with muscular contractions by ICS. Combination of three tasks were presented at the top row. F, finger task; W, wrist task; A, arm task. ICS column represents 5 groups with different muscular contractions by ICS. 
Characteristics of PTN activity in the three tasks

Table 1 shows the response pattern of the whole precentral neurons disregarding the difference of PTNs and non-PTNs. However, it is desirable to study these two groups separately, because multisegmental innervation was also observed in reticulo-, vestibulo, or rubrospinal fibers (ABZug et al., 1974; PETERson et al., 1975; SHINODA et al., 1977), and branching of the vestibulospinal fibers differed from the corticospinal fibers (Shinoda, personal communications).

Five neurons on which antidromic stimulation were not tested were excluded from both tables 2 and 3 . Tables 2 and 3 contained features similar to Table 1 . Most of the neurons in elbow-, shoulder-, and trunk-groups responded only to the arm task, while the majority of finger- and wrist-groups were related to more than two tasks. It is noticeable that two out of 5 finger-PTN $(40 \%)$ responded only to the arm task (A), but not to the finger task. A sampling bias due to a small number of finger-PTNs may be the main reason for this result. In conclusion, PTNs and whole cortical neurons had similar characteristics in response to the three tasks; PTNs of finger- and wrist-groups changed their activities in various ways during the three tasks, while most of elbow-, shoulder-, or trunk-neurons responded solely to the arm task.

Characteristics of non-PTN responses to the three tasks

A similar analysis was conducted on non-PTNs (see Table 3). As shown in Table 3, a few neurons in finger- and wrist-groups responded to a single task, either with finger, wrist, or arm. Most of the neurons in these two groups changed their activities in association with a combination of two or three tasks. The most common type of the finger-group were those related to all three tasks $(5 / 12,41.7 \%)$.

Table 2. Relation of PTN firing patterns and muscular contractions evoked by ICS.

\begin{tabular}{|c|c|c|c|c|c|c|c|c|}
\hline \multirow[b]{2}{*}{ ICS } & \multicolumn{8}{|c|}{ Task } \\
\hline & $\mathrm{F}$ & W & A & $F+W$ & $\mathrm{~F}+\mathrm{A}$ & $\mathrm{W}+\mathrm{A}$ & $\mathrm{F}+\mathrm{W}+\mathrm{A}$ & $\begin{array}{c}\text { Total } \\
(\%)\end{array}$ \\
\hline Finger & 0 & 0 & $\begin{array}{r}2 \\
(40)\end{array}$ & $\left.\begin{array}{r}1 \\
(20\end{array}\right)$ & 0 & 0 & $\begin{array}{r}2 \\
(40)\end{array}$ & $\begin{array}{c}5 \\
(100)\end{array}$ \\
\hline Wrist & 0 & $\begin{array}{c}1 \\
(8.3)\end{array}$ & $\begin{array}{c}3 \\
(25.0)\end{array}$ & 0 & $\begin{array}{c}3 \\
(25.0)\end{array}$ & $\begin{array}{c}4 \\
(33.3)\end{array}$ & $\begin{array}{c}1 \\
(8.3)\end{array}$ & $\begin{array}{r}12 \\
(100)\end{array}$ \\
\hline Elbow & 0 & $\begin{array}{c}1 \\
(9.1)\end{array}$ & $\begin{array}{c}8 \\
(72.7)\end{array}$ & 0 & 0 & $\begin{array}{c}1 \\
(9.1)\end{array}$ & $\begin{array}{l}1 \\
(9.1)\end{array}$ & $\begin{array}{c}11 \\
(100)\end{array}$ \\
\hline Shoulder & $\begin{array}{c}1 \\
(4.2)\end{array}$ & $\begin{array}{c}1 \\
(4.2)\end{array}$ & $\begin{array}{c}13 \\
(54.2)\end{array}$ & 0 & 0 & $\begin{array}{c}4 \\
(16.7)\end{array}$ & $\begin{array}{c}5 \\
(20.8)\end{array}$ & $\begin{array}{r}24 \\
(100)\end{array}$ \\
\hline Trunk & 0 & $\begin{array}{c}1 \\
(12.5)\end{array}$ & $\begin{array}{r}4 \\
(50 \quad)\end{array}$ & 0 & 0 & $\begin{array}{c}2 \\
(25.0)\end{array}$ & $\begin{array}{c}1 \\
(12.5)\end{array}$ & $\begin{array}{c}8 \\
(100)\end{array}$ \\
\hline Total & $\begin{array}{c}1 \\
(1.7)\end{array}$ & $\begin{array}{c}4 \\
(6.7)\end{array}$ & $\begin{array}{c}30 \\
(50.0)\end{array}$ & $\begin{array}{l}1 \\
(1.7)\end{array}$ & $\begin{array}{l}3 \\
(5.0)\end{array}$ & $\begin{array}{c}11 \\
(18.3)\end{array}$ & $\begin{array}{c}10 \\
(16.7)\end{array}$ & $\begin{array}{c}60 \\
(100)\end{array}$ \\
\hline
\end{tabular}

Legends same as in Table 1.

Vol. 33, No. 3, 1983 
Table 3. Relation of non-PTN firing patterns and muscular contractions evoked by ICS.

\begin{tabular}{|c|c|c|c|c|c|c|c|c|}
\hline \multirow[b]{2}{*}{ ICS } & \multicolumn{8}{|c|}{ Task } \\
\hline & $F$ & W & A & $\mathbf{F}+\mathbf{W}$ & $\mathbf{F}+\mathrm{A}$ & $\mathrm{W}+\mathrm{A}$ & $\mathrm{F}+\mathrm{W}+\mathrm{A}$ & $\begin{array}{c}\text { Total } \\
(\%)\end{array}$ \\
\hline Finger & 0 & $\begin{array}{c}1 \\
(8.3)\end{array}$ & $\begin{array}{c}1 \\
(8.3)\end{array}$ & $\begin{array}{c}1 \\
(8.3)\end{array}$ & $\begin{array}{c}1 \\
(8.3)\end{array}$ & $\begin{array}{c}3 \\
(25.0)\end{array}$ & $\begin{array}{c}5 \\
(41.7)\end{array}$ & $\begin{array}{r}12 \\
(100)\end{array}$ \\
\hline Wrist & 0 & $\begin{array}{l}1 \\
(6.7)\end{array}$ & $\begin{array}{l}1 \\
(6.7)\end{array}$ & $\begin{array}{c}2 \\
(13.3)\end{array}$ & $\begin{array}{l}1 \\
(6.7)\end{array}$ & $\begin{array}{c}6 \\
(40.0)\end{array}$ & $\begin{array}{c}4 \\
(26.7)\end{array}$ & $\begin{array}{r}15 \\
(100)\end{array}$ \\
\hline Elbow & 0 & 0 & $\begin{array}{c}4 \\
(66.7)\end{array}$ & 0 & 0 & $\begin{array}{c}1 \\
(16.7)\end{array}$ & $\begin{array}{c}1 \\
(16.7)\end{array}$ & $\begin{array}{r}6 \\
(100)\end{array}$ \\
\hline Shoulder & 0 & $\begin{array}{c}1 \\
(5.3)\end{array}$ & $\begin{array}{c}11 \\
(57.9)\end{array}$ & 0 & $\begin{array}{c}3 \\
(15.8)\end{array}$ & $\begin{array}{c}2 \\
(10.5)\end{array}$ & $\begin{array}{c}2 \\
(10.5)\end{array}$ & $\begin{array}{c}19 \\
(100)\end{array}$ \\
\hline Trunk & 0 & 0 & $\begin{array}{c}4 \\
(50.0)\end{array}$ & 0 & $\begin{array}{c}1 \\
(12.5)\end{array}$ & $\begin{array}{c}1 \\
(12.5)\end{array}$ & $\begin{array}{c}2 \\
(25.0)\end{array}$ & $\begin{array}{r}8 \\
(100)\end{array}$ \\
\hline Total & 0 & $\begin{array}{c}3 \\
(5.0)\end{array}$ & $\begin{array}{l}21 \\
(35.0)\end{array}$ & $\begin{array}{c}3 \\
(5.0)\end{array}$ & $\begin{array}{c}6 \\
(10.0)\end{array}$ & $\begin{array}{l}13 \\
(21.7)\end{array}$ & $\begin{array}{l}14 \\
(23.3)\end{array}$ & $\begin{array}{r}60 \\
(100)\end{array}$ \\
\hline
\end{tabular}

Legends same as in Table 1.

The second largest group responded to wrist and arm tasks (3/12, 25\%).

In the wrist-group, the majority were those $(6 / 15,40 \%)$ responding to wrist and arm tasks. Another $4(4 / 15,26.7 \%)$ changed their activities in all three tasks. On the contrary, more than half of non-PTNs in elbow-, shoulder-, and trunkgroups responded only to the arm task. Smaller numbers of neurons changed their activities in association with more than one tasks. In conclusion, fingerand wrist-non-PTNs changed activities during multi-tasks, while those of elbow-, shoulder-, and trunk-groups responded to the arm task.

\section{DISCUSSION}

The present experiment demonstrated that most neurons in elbow-, shoulder-, and trunk-groups were associated primarily with the arm task, while the majority of finger- and wrist-groups altered their activities in association with more than two tasks. In this paper, elbow-, shoulder-, and trunk-groups are termed the proximo-truncal group, and finger- and wrist-groups are called the distal group.

Possible explanations for the multiple-task related neuronal activities. Since the proximo-truncal group was primarily associated with the arm task, it is consistent with the concept of the somatotopical organization in the motor cortex (Asanuma and Rosen, 1972; Kwan et al., 1978; Strick and Preston, $1982 \mathrm{a}, \mathrm{b}$; WoOLSEY et al., 1958). The diversity of the neuronal activity of the distal group during the three tasks and the existence of multiple-task related neurons of the proximo-truncal group require explanations.

The first explanation for neurons related to multiple tasks may be based on the diverse innervation of a single corticospinal neuron into multiple segments of 
the spinal cord (FutAmi et al., 1979; HAYes and Rusitoni, 1981; Scheibel and SCHeiBel, 1966; ShinOda, 1978; Shinoda and YAMAGUCHI, 1978; Shinoda et al., $1979,1981)$. If activities of neurons are related to a single motor task, their axons probably terminate in a limited number of motoneuron plexuses functionally related to a specific kind of motor performance. Consequently their terminal areas may be confined to a smaller number of spinal segments. On the other hand, if activities are related to multiple task performances, they may innervate several motoneuron plexuses with different functions; some motoneurons are activated during one task, and others, during another. In this instance, such corticospinal neurons may innervate more spinal segments than those related only to a single motor performance.

An alternative explanation is that neuronal activities which changed in multiple tasks may reflect a manner of activity of a single muscle involved in the tasks. Some distal forelimb muscles (finger muscles for example) might be used in all three tasks to grip the handle. Then neurons innervating such muscles became active during all three tasks. Therefore, neuronal activities observed during the three tasks may imply no more than a link of neurons to such muscles.

We will consider these two possibilities in the finger-group, because multi-task related neurons of the finger-group were most debatable in the present study. Therefore, if it is approved for the finger-group that the multi-task activity could be attributed to the multi-segmental branching of a single corticospinal axon, then it is allowed to apply the same reasoning to multi-task related neurons in other groups.

In favour of the first explanation, KWAN and his collaborators (1978) reported that a threshold current could elicit a motor response involving two joints. Although a possibility still remained that intracortical microstimulation made several neurons discharge at once in the vicinity of the electrode, their results supported the interpretation that the activity of multi-task related neurons in the present experiment was a functional expression of multisegmental collaterals of the corticospinal neuron. This argument was further supported by the data that a single corticomotoneuron linked disynaptically with forearm and upper arm muscles (FeTz and FinocCHIO, 1978).

An alternative explanation is that the multiple task related neurons only linked to single muscles which were involved in three tasks. This possibility is to be discussed with the 7-finger neurons showing activity change during all three tasks. They were the most suspect case of this possibility. Two of the seven neurons showed decrease in activity during the handle movements in the arm task, but increased during the holding period of the handle. This means that the activity of these two neurons were not correlated with the movement itself, but with holding or stabilizing the handle. Consequently, it is more plausible to consider that these two neurons innervated single muscles which were used to grip the handle and were activated in finger, wrist and arm tasks. Two other neurons, however, showed a reciprocal change in activity during the handle movement; increase in one direction 
and decrease in the other. Therefore, it is more plausible to consider for these two neurons that they controlled different muscles with different functions rather than innervated single muscles. The remaining three showed increase in activity in one direction during arm movements, but did not show appreciable changes in another. However, considering their relationship of discharge to movements, it is reasonable to assume that they were more similar to the second two neurons; activities changed during movements, but not during holding of the handle. Therefore, their activation during the three tasks, could be correlated with the multisegmental termination of a corticospinal neuron in the spinal cord.

In the present experiment, no finger-neuron was specifically associated with the finger task. One explanation for this is a sampling bias, because the total number of the finger-neuron did not seem large enough. The second possibility is that some finger-neurons innervated more than one muscle. The third one is that other finger-neurons innervated a single muscle which might be active during three movements for stabilizing the handle. For the last two possibilities, they were referred in detail in the preceding paragraphs. Probably all three factors combined to nullify the finger-neurons which were specifically related to the finger task.

Consideration of previous studies. Using a spike triggered averaged technique, FETZ and CHENEY demonstrated that some corticospinal neurons made direct synaptic contacts to motoneurons of different muscles (corticomotoneurons; Fetz and Cheney, 1978, 1979; FeTZ and FinocChio, 1971, 1975). Their findings confirmed evidence of the multi-segmental branching of the corticospinal neuron, and accordingly, they proposed a concept of "muscle field."

A similar concept of "motor field" has also been offered (LEMON, 1981 a, b; LEMON et al., 1980). But the relevance of both concepts to the trunk or the proximal forelimb muscles has not satisfactorily been examined. Therefore, it seems worthy to consider whether the concepts are applicable to proximal muscles. Our present data on PTNs showed that a considerable number of the proximal PTNs were associated with two or three tasks, suggesting that proximal PTNs may innervate several different motoneuron plexuses. Consequently they could innervate several different muscles. Therefore, a concept similar to "muscle field" or "motor field" may be applied to neurons in the motor cortex controlling trunk or proximal limb muscles.

The present experiment did not show a significant difference between PTNs and non-PTNs in response to three tasks. Thus a concept similar to "muscle field" or "motor field" might be applicable to the indirect cortico-spinal systems, because multi-segmental branchings were observed in the rubro-, reticulo-, or vestibulospinal fibers (AbZug et al., 1974; Peterson et al., 1975; Shinoda et al., 1977), which constituted the main indirect cortico-spinal system. But it must be remined that a moderate modification would be required in application of the concepts to non-PTNs.

The authors wish to express their thanks to Mrs. T. Miwa for her invaluable assistance. 


\section{REFERENCES}

Abzug, C., Maeda, M., Peterson, B. M., and Wilson, V. J. (1974) Cervical branching of lumbar vestibulospinal axons. J. Physiol. (Lond.), 243: 499-522.

AsAnuma, H. and Rosen, I. (1972) Topographical organization of cortical efferent zones projecting to distal forelimb muscles in the monkey. Exp. Brain Res., 14: 243-256.

Asanuma, H., Zarzecki, P., Jankowska, E., Homgo, T., and Marcus, S. (1979) Projection of individual pyramidal tract neurons to lumbar motoneuron pools of the monkey. Exp. Brain Res., 34: 73-89.

Conrad, B., Meyer-Lohmann, J., Matsunami, K., and Brooks, V. B. (1975) Precentral unit activity following torque pulse injections into elbow movements. Brain Res., 94: 219-236.

EvarTs, E. V. (1965) Relation of discharge frequency and conduction velocity in pyramidal tract neurons. J. Neurophysiol., 28: 216-228.

EVARTS, E. V. (1966) Pyramidal tract neuron activity associated with a conditioned hand movement in the monkey. J. Neurophysiol., 29: 1011-1027.

EvarTs, E. V. (1973) Motor cortex reflexes associated with learned movement. Science, 179: 501-503.

EVARTS, E. V. and TANII, J. (1976) Reflex and intended responses in motor cortex pyramidal tract neurons of monkey. J. Neurophysiol., 39: 1069-1080.

Fetz, E. E. and Cheney, P. D. (1978) Muscle fields of primate corticomotoneuronal cells. J. Physiol. (Paris), 74: 239-245.

FetZ, E. E. and Cheney, P. D. (1979) Muscle fields and response properties of primate corticomotoneuronal cells. In: Prog. Brain Res., Vol. 50, Control of Posture and Movement, ed. by Granit, R. and Pompeiano, O. Elsevier, Amsterdam, London, and New York, pp. 137-146.

FetZ, E. E. and Finocchio, D. V. (1971) Correlations between activity of motor cortex cells and arm muscles during operantly conditioned response patterns. Exp. Brain Res., 23: 217-240.

Fetz, E. E. and Finocchio, D. V. (1975) Correlations between activity of motor cortex cells and arm muscles during operantly conditioned response patterns. Exp. Brain Res., 23: 217-240.

Fromm, C. and Evarts, E. V. (1977) Relation of motor cortex neurons to precisely controlled and ballistic movements. Neurosci. Lett., 5: 259-265.

Futami, T., Shinoda, Y., and Yokota, T. (1979) Spinal axon collaterals of corticospinal neurons identified by intracellular injection of horseradish peroxidase. Brain Res., 164: 279-284.

HAMADA, I. and KUBotA, K. (1979) Monkey pyramidal tract neurons and changes of movement parameters in visual tracking. Brain Res. Bull., 4: 249-257.

HAYES, N. L and Rusitoni, A. (1981) Descending projections from brainstem and sensorimotor cortex to enlargements in the cat. Exp. Brain Res., 41: 89-107.

KWAN, H. C., MACKAY, W. A., Murphy, J. T., and Wong, Y. C. (1978) Spatial organization of precentral cortex in awake primates. II. Motor outputs. J. Neurophysiol., 41: 1120-1131.

LEMON, R. N. (1981a) Functional properties of monkey motor cortex neurones receiving afferent input from the hand and fingers. J. Physiol. (Lond.), 311: 497-519.

LEMON, R. N. (1981b) Variety of functional organization within the monkey motor cortex. $J$. Physiol. (Lond.), 311: 521-540.

Lemon, R. N. and Porter, R. (1976a) Afferent input to movement-related precentral neurones in conscious monkeys. Proc. R. Soc. Lond. (Biol.), 194: 313-339.

LEMON, R. N. and PORTER, R. (1976b) Relationship between the activity of precentral neurones during active and passive movements in conscious monkeys. Proc. R. Soc. Lond. (Biol.), 194: 341-373.

Vol. 33, No. 3, 1983 
Lemon, R. N., Tilburg, K. Van, and Kuypers, H. G. J. M. (1980) Motor fields of monkey area 4 neurones active during precision grip. Prog. XXVIIIth Int. Congr. Physiol. Sci., p. 545 .

Matsunami, K. and Hamada, I. (1978) Precentral neuronal activities associated with the upper limb movement in monkeys. J. Physiol. (Paris), 74: 319-322.

MATSUNAMI, K. and Hamada, I. (1981) Characteristics of ipsilateral movement related neuron in the motor cortex of the monkey. Brain Res., 207: 29-42.

Murphy, J. T., Kwan, H. C., MacKaY, W. A., and Wong, Y. C. (1978) Spatial organization of precentral cortex in awake primates. III. Input-output coupling. J. Neurophysiol., 41: $1132-1139$.

Murphy, J. T., Kwan, H. C., MacKay, W. A., and Wong, Y. C. (1982) Activity of primate precentral neurons during voluntary movements triggered by visual signals. Brain Res., 236: 429-449.

Peterson, B. W., Maunz, R. A., Pitts, N. G., and Mackel, R. G. (1975) Patterns of projection and branching of reticulospinal neurons. Exp. Brain Res., 23: 333-351.

Porter, R. and Lewis, M. McD. (1975) Relationship of neuronal discharges in the precentral gyrus of monkeys to the performance of arm movements. Brain Res., 98: 21-36.

PorTer, R., Lewis, M. McD., and HoRne, M. (1971) Analysis of patterns of natural activity of neurones in the precentral gyrus of conscious monkeys. Brain Res., 34: 99-113.

Scheibel, M. E. and Scheibel, A. B. (1966) Terminal axonal patterns in the cat spinal cord. I. The lateral corticospinal tract. Brain Res., 2: 333-350.

Schmidt, E. M., Jost, R. G., and David, K. K. (1975) Re-examination of the force relationship of cortical cell discharge patterns with conditioned wrist movements. Brain Res., 83: 213223.

SHINODA, Y. (1978) Intraspinal multiple projections of single corticospinal neurons in the cat and monkey. Integrative Control Funct. Brain, 1: 137-151.

Shinoda, Y., Arnold, A. P., and Asanuma, H. (1976) Spinal branching of corticospinal axons in the cat. Exp. Brain Res., 26: 215-234.

Shinoda, Y., Ghez, C., and Arnold, A. P. (1977) Spinal branching of rubrospinal axons in the cat. Exp. Brain Res., 30: 203-218.

Shinoda, Y. and YAmAGUCHI, T. (1978) The intraspinal branching patterns of fast and slow pyramidal tract neurons in the cat. J. Physiol. (Paris), 74: 237-238.

Shinoda, Y., Yokota, J., and FutAMI, T. (1981) Divergent projection of individual corticospinal axons to motoneurons of multiple muscles in the monkey. Neurosci. Lett., 23: 7-12.

Shinoda, Y., ZarzeCKI, P., and Asanuma, H. (1979) Spinal branching of pyramidal tract neurons in the monkey. Exp. Brain Res., 34: 59-72.

Smith, A. M., HePp-Reymond, M. C., and Wyss, U. R. (1975) Relation of activity in precentral cortical neurons to force and rate of force change during isometric contractions of finger muscles. Exp. Brain Res., 23: 315-332.

Strick, P. L. and Preston, J. B. (1982a) Two representations of the hand in area 4 of a primate. I. Motor output organization. J. Neurophysiol., 48: 139-149.

StRick, P. L. and Preston, J. B. (1982b) Two representations of the hand in area 4 of a primate. II. Somatosensory input organization. J. Neurophysiol., 48: 150-159.

TANJI, J. and EvarTs, E. V. (1976) Anticipatory activity of motor cortex neurons in relation to direction of an intended movement. J. Neurophysiol., 39: 1062-1068.

WOOLSEY, C. N. (1958) Organization of somatic sensory and motor area of the cerebral cortex. In: Biological and Biochemical Basis of Behavior, ed. by Harlow, H. F. and Woolsey, C. N. Univ. Wisconsin Press, Madison, Wisc., pp. 63-81. 